\title{
Secondhand smoke exposure among young adults in a developing country - a Jordanian case
}

This article was published in the following Dove Press journal:

Substance Abuse and Rehabilitation

23 April 2013

Number of times this article has been viewed

\author{
Linda Haddad' \\ Nesrin Abu Baker ${ }^{2}$ \\ Omar El-Shahawy ${ }^{3}$ \\ Nahla Al-Ali² \\ Tamadur Shudayfat ${ }^{2}$ \\ 'Virginia Commonwealth University, \\ School of Nursing and Institute for \\ Drug and Alcohol Studies, Richmond, \\ VA, USA; ${ }^{2}$ Jordan University of Science \\ and Technology, School of Nursing, \\ Irbid, Jordan; ${ }^{3}$ Social and Behavioral \\ Health Department, School of \\ Medicine, Virginia Commonwealth \\ University, Richmond, VA, USA
}

Correspondence: Linda Haddad Virginia Commonwealth University, School of Nursing and Institute for Drug and Alcohol Studies, Richmond,

VA, 23298, USA

Tel +l 8048280433

Fax +l 8048287743

Email Ihaddad2@vcu.edu
Abstract: Secondhand smoke (SHS) exposure is a potentially preventable environmental pollutant that remains a major global public health concern. A descriptive cross-sectional design was used to assess secondhand smoke exposure, knowledge, attitudes, and avoidance behaviors, as well as policy agreements related to SHS among young adult university students in the northern part of Jordan. A convenience sample of 800 university students from three public universities participated in the present study. They completed four questionnaires: the Sociodemographic Questionnaire, the Household SHS Exposure Questionnaire, the Knowledge and Attitudes Toward SHS Exposure Questionnaire, and the Avoidance of SHS Exposure Scale. Findings showed that SHS exposure among nonsmoking university students was $96 \%$. In addition, the mean hours of exposure per day was 4.64 hours ( $\operatorname{standard~deviation~}=4.28$ ), and the mean days of exposure per week was 5.14 days (standard deviation $=2.1$ ). Based on the students reported high hours of exposure, our results suggest that even though a student has knowledge of the dangers of SHS and suitable avoidance behaviors, he or she is unable to avoid SHS. Advocacy for effective interventions to avoid exposure to SHS should be initiated for Jordanian society as a whole.

Keywords: secondhand smoking, college students, Jordan, exposure

\section{Background}

Smoking is highly prevalent among Jordanians; Jordan has the fourth-highest smoking rate among Arab countries, despite its compliance with most of the recommended tobacco use prevention initiatives. ${ }^{1}$ The latest estimates published in 2009 shows that the prevalence of cigarette smoking among college students is estimated to be $62.7 \%$ and reaches $9.8 \%$ among women. ${ }^{2}$ Health warnings are present on cigarette labels, but few cessation services are provided. ${ }^{3}$ Furthermore, there is a growing concern over the increased incidence of smoking among children, who may start as young as 9 years of age. ${ }^{4}$ The prevalence of tobacco use among university students in Jordan was $56.9 \%$ among males and $11.4 \%$ for females. ${ }^{5}$ Among school students between the ages of 13 and 15 years it was reported to be $31.6 \%$ among males and $24.0 \%$ among females. ${ }^{6}$ Also, the prevalence of smoking is increasing, especially among college students. ${ }^{7}$ In fact, the higher smoking prevalence among Jordanian college students makes secondhand smoke exposure an important risk factor for nonsmokers. Further, smoking practices at home promote the permissiveness of smoking among young adults by establishing a social norm for smoking. Decreasing secondhand smoke exposure in the home by prohibiting smoking in private residences will influence the social acceptability of smoking and thus create the desired stigma against smoking in the eyes of adolescents. ${ }^{8-11}$ 
Jordan has an extensive history of tobacco-control policies and programs that have shaped its current tobaccocontrol infrastructure. Jordan's initial smoke-free policy was part of a public health law issued in $1977 .{ }^{12}$ Recently, Jordan's public health law prohibits smoking in public and private buildings, as well as in all enclosed public venues including hospitals, healthcare centers, schools, cinemas, libraries, museums, nongovernmental buildings, public transport vehicles, airports, closed playgrounds, shopping malls, restaurants, and lecture halls. ${ }^{13-16}$

A comprehensive literature review revealed one Jordanian study that assessed levels of SHS exposure among employed Jordanian women working in public university institutions. ${ }^{17}$ This study found that women were regularly exposed to secondhand smoke (SHS) in various locations in daily life. Specifically, the study found that women encountered a mean of 5.5 (standard deviation \pm 5.5 ) hours per day of SHS exposure. Additionally, women reported on an average of 6 days per week (standard deviation $(\mathrm{SD})=6.2$ ) of SHS exposure in any setting. ${ }^{17}$

Knowing the magnitude of the problem regarding smoking could be helpful in directing and reinforcing both policy and legislation in Jordan. To date, no study has compared multiple university populations on knowledge, attitudes, and avoidance behaviors toward SHS.

In summary, it can be concluded that university students' views regarding tobacco-control policies can help university administrators and tobacco-control advocates implement appropriate prevention and control programs. The specific aims of this study are: (1) to measure the level of exposure of SHS among university students in the three largest public universities in northern Jordan; and (2) to assess the students' knowledge, attitudes, and avoidance behaviors toward SHS. The findings will serve as foundational data on college students' level of exposure and perceptions about SHS. This foundational data will assist in developing tobacco-control programs aimed at improving college students' health.

\section{Methods}

\section{Setting and population}

Data were collected using a convenience sample of university students at three public universities in northern Jordan: Jordan University of Science and Technology located in Irbid; Yarmouk University located in Irbid; and Al al-Bayt University located in Mafraq. The three universities host around 60,000 undergraduate students in a variety of educational disciplines.
The students were a largely homogeneous group in terms of ethnic background, socioeconomic status, and sex. The needed sample size was estimated to be 800 students, assuming a prevalence of smoking of 55\% and accepting a margin error no greater than 5\%, with a confidence interval of $95 \%$. A combined total of 800 students from these three universities participated in this study: 248 from Jordan University of Science and Technology; 152 from Al al-Bayt University; and 400 from Yarmouk University. Exclusion criteria included students younger than 18 years of age and students who smoked.

\section{Data collection protocol}

This study was approved as an exempt level study by the Institutional Review Board of Jordan University of Science and Technology. Appropriate permissions were obtained from Al al-Bayt University and Yarmouk University through formal letters from the Deanship of Research of Jordan University of Science and Technology. A list of all general elective classes was obtained from the registration offices of the three universities during a 3-month period, from May-July 2011; two of the study investigators collected the data. They distributed 2000 flyers and letters across the three universities' general elective classes. The flyer and letter explained the purpose of the study and invited students who were nonsmokers or had not smoked the year prior to volunteer for the study. The investigators made a prior arrangement with specific elective classes that ensured variability of the students' demographics, such as area of study concentration and the current year of study. The investigators distributed survey packets during classroom sessions. The survey packet included a cover letter, a demographic data sheet, and two questionnaires along with a return envelope. Potential participants were informed that participation in this study was voluntary. Faculty members were asked to leave during the completion of the questionnaire. Informed consent was obtained from students who agreed to participate. The participants were informed that their responses would remain anonymous.

The participants took approximately 15 minutes to complete the questionnaire, after which the researchers collected the survey packets. Of the 823 students who were given survey packets, 813 returned the questionnaires, which yielded a response rate of $98.8 \%$. Of those, 800 surveys were completed and subsequently used for data analysis. Thirteen surveys were excluded from the final analysis due to a high proportion of missing data. 


\section{Instruments}

The SHS data was collected using four questionnaires:

1. Sociodemographic Questionnaire: Consisting of seven items (age, sex, nationality, specialization, year of study, smoking status, and family income). Two additional items were added to the first section regarding: (1) whether they were aware of any university smoking policy; and (2) if they had been invited to attend any university smokingprevention program.

2. Household Secondhand Smoke Exposure Questionnaire: The questionnaire was compiled from surveys by Wipfli et $\mathrm{al}^{18}$ and Glasgow et $\mathrm{al}^{19}$ and translated into Arabic. This assessed the SHS exposure site (home, work, elsewhere). The questionnaire had four sections: general information and demographic characteristics; smoking behavior; exposure to SHS; and attitudes toward the SHS control policies. Each section consisted of five questions with responses on a 4-point Likert scale ( $1=$ disagree; $2=$ somewhat disagree; $3=$ somewhat agree; and 4 = agree).

3. Knowledge and Attitudes Toward SHS Exposure Questionnaire: This questionnaire covered two domains: (1) knowledge of the adverse effects associated with SHS exposure; and (2) attitudes and personal feelings toward SHS exposure. The questionnaire developed by Kurtz et $\mathrm{al}^{20}$ included twelve items that assess people's knowledge and attitudes toward SHS exposure. The subscale was in the form of a 5-point Likert response scale ( $1=$ strongly agree; $2=$ agree; $3=$ undecided $; 4=$ disagree; $5=$ strongly disagree). Total scores of the eight items ranged from 8 to 40 . The ranges from 8 to 16 were strongly disagree and disagree, 25 to 40 were strongly agree and agree, and between 17 to 24 were undecided.

4. Avoidance of SHS Exposure Scale: This scale assessed avoidance or preventive efforts undertaken by the person when exposed to SHS in their immediate environment; the scale was developed by Martinelli. ${ }^{21}$ This scale included 19 items that assessed the participants' efforts to prevent SHS exposure. This subscale was in the form of a 4-point Likert response scale $(1=$ almost always true; 2 = usually true, $3=$ usually not true; and $4=$ almost never true). Cumulative scores were summed and yielded a range of 19-76, with higher scores indicating a greater avoidance of SHS.

In this study, Arabic versions of the four questionnaires were used. They were translated and validated by Gharaibeh et al. ${ }^{17}$

\section{Pilot study}

A pilot study was conducted to identify the practical limitations of the instrument and the difficulties that might appear during its application in the main study, as well as to calculate the alpha coefficient reliability of the instrument. In addition, the pilot study was used to assess understanding of the questions and the time taken to complete the questionnaire. Consequently, modifications were made before applying the study to the main sample.

A pilot study was carried out in May 2011 using a convenience sample of 50 students. The inclusion criteria of the pilot sample were similar to the study sample criteria. In addition, the participants of the pilot study were recruited from the three universities, according to the university proportion in the sample size: Yarmouk University $(\mathrm{YU})=25$; Jordan University of Science and Technology $($ JUST $)=15$; and $\mathrm{Al}$ al-Bayt University $(\mathrm{AABU})=10$.

Almost all students who participated in the pilot study reported that the title of the study was interesting and that the questionnaire items were clear and easy to understand. Ten to 15 minutes were needed to complete the questionnaires. One suggested change was incorporated - according to the feedback of the participants - to enhance readability and content validity. The change added this note before Question 2.2 (if there is no smoker, members in the household do not answer Question 2:2 and Question 2:3). Reliability coefficients (Cronbach's alpha) for pilot study subscales (knowledge, attitudes, and avoidance efforts) were $0.9,0.8$, and 0.7 , respectively.

\section{Data analysis}

JMP Pro 12.0 (SAS Institute Inc, Cary, NC, USA) was used for data analysis. The alpha level was set at 0.05 to determine statistical significance. Descriptive analyses were conducted to characterize self-reported SHS exposure, university smoking policies, knowledge and attitudes toward SHS exposure, and SHS avoidance practices. Chi-square tests were performed to estimate the bivariate difference between antismoking attitudes in university policies, and smoking and avoidance of SHS exposure by subjects. An analysis of variance test was performed to compare the means across more than two groups in the study, while a $t$-test was performed to compare the mean of two groups in the study.

\section{Results \\ Sample characteristics}

Fifty percent of the sample was from Yarmouk University $(n=400) ; 31 \%$ was from Jordan University of Science 
and Technology $(\mathrm{n}=248)$; and $19 \%$ was from Al al-Bayte University $(\mathrm{n}=152)$. Participants' ages ranged between $18-25$ years old, with a mean of 20.4 years old $(S D \pm 1.75)$. Nearly $55 \%(n=439)$ of them were females, and $45 \%$ were males $(n=361)$. Fifty-four percent $(n=431)$ were in their second or third year of study.

\section{Household SHS exposure}

SHS results revealed that $51 \%$ of all participants $(n=410)$ reported that they had members in their household who smoked inside the home, while only $15.5 \%$ of all participants $(n=124)$ reported they had a member in their household who smoked outside the home. In contrast, $33 \%$ of all participants $(n=266)$ reported they had no smoking members in their household.

When the students were asked if any of their household members had smoked around them in the past 30 days, inside or outside of their homes, around $61 \%(n=487)$ reported that they had done so. When asked to estimate daily and weekly SHS exposure (indoors and outdoors), results showed that almost all participants were exposed to SHS (96\%). In addition, the mean hours of exposure per day was 4.6 hours $(\mathrm{SD}=4.2)$, and the mean days of exposure per week was 5.1 days $(\mathrm{SD}=2.1)$ in any setting.

Despite the fact that university antismoking policies existed at the time of the survey, when participants were asked about the presence of such policies, only 50\% reported being aware of these policies. Nearly $40 \%$ did not think that their university had antismoking policies, and 10\% were not aware if such policies existed.

Students in the study were asked to identify locations of SHS exposure. The noncumulative percentage of exposure (response of "always, and often") results revealed the university restaurant or cafe was the main source of exposure $(74 \% ; n=595)$. The second identified source of exposure was public transportation vehicles $(73 \% ; n=583)$, and $69 \%(n=550)$ reported SHS exposure from public places, such as waiting rooms and bus stations. While 59\% $(\mathrm{n}=475)$ reported SHS exposure from university educational facilities, they also reported exposure to SHS in private worksites (40\%), home (44\%), and governmental worksites (54\%).

To provide a more comprehensive comparison between students' demographic variables and the cumulative daily hours of SHS exposure, an independent sample $t$-test was used to investigate the relationship between a student's SHS exposure hours per day and his or her sex. The current results showed no statistically significant difference between the student's SHS exposure hours per day and sex: $(t[798]=-1.0 ; P=0.21)$.
Also, the results of the one-way analysis of variance test between the student's university and SHS exposure hours per day revealed no significant difference between university groups (YU, JUST, AABU) and the student's exposure to SHS $(F[2,797]=1.17 ; P=0.18)$. Further, the results of the one-way analysis of variance (ANOVA) between the student's year of study (first year, second year, third year, fourth year, and above) and SHS exposure hours per day revealed no significant difference between university groups $(F[2,797]=2.4 ; P=0.09)$.

However, there was a significant difference between the students' area of study concentration groups (medical, engineering, science, and art) and the students' exposure to SHS hours per day $(F[796]=2.8 ; P=0.03)$. In addition, post hoc comparisons using the Tukey honestly significant difference test indicated that medical students (mean $[\mathrm{M}]=3.6092 ; \mathrm{SD}=3.41800)$ were significantly less exposed to SHS than art students $(\mathrm{M}=4.9570 ; \mathrm{SD}=4.8582)$.

\section{Knowledge and attitudes toward SHS exposure}

The results reveal that almost all students (93.8\%) perceived SHS exposure as “dangerous for a nonsmoker's health." This percentage decreased slightly (51.9\%) when students were asked about the association of SHS exposure and lung cancer in nonsmokers. Negative perceptions toward SHS exposure remained consistent through all responses - above $90.8 \%$. Subjects also expressed their support that public places should be smoke-free (Table 1).

Table 2 presents the findings of the knowledge and attitude items regarding exposure to SHS. The majority of respondents had suitable knowledge of the negative health impacts of SHS on adults and children. They either agreed or strongly agreed with the described negative health effects of SHS exposure on adults. This included general adults' health $(66.2 \%)$, heart and lung disease $(75.5 \%)$, shortening of people's lives $(90.3 \%)$, and low infant birth weight $(61.2 \%)$. On the other hand, when exploring the participants' attitudes toward SHS exposure, only $38 \%$ of the students expressed that they will not let visitors smoke in their homes. However, the percentage was slightly higher $(50 \%)$ when the students expressed that they would ask people around them to put out their cigarettes.

When summed to create a total score for knowledge of SHS exposure, the group mean was $25(\mathrm{SD}=4.5)$ with a possible range of 6-31 points. The scoring method applied indicates that higher scores describe more accurate or better knowledge about SHS. When summed to create a total 
Table I Findings from the SHS exposure scale $(\mathrm{N}=800)$

\begin{tabular}{|c|c|c|c|c|}
\hline Items & Disagree \% & $\begin{array}{l}\text { Somewhat } \\
\text { disagree \% }\end{array}$ & $\begin{array}{l}\text { Somewhat } \\
\text { agree \% }\end{array}$ & Agree \% \\
\hline $\begin{array}{l}\text { I. Tobacco smoke is dangerous for } \\
\text { nonsmoker's health }\end{array}$ & 3.8 & 2.4 & 17.8 & 76 \\
\hline $\begin{array}{l}\text { 2. Children who are exposed to tobacco } \\
\text { smoke have more illnesses, such as colds }\end{array}$ & 3.9 & 5 & 27.5 & 63.6 \\
\hline $\begin{array}{l}\text { 3. Exposure to tobacco smoke can cause } \\
\text { lung cancer in nonsmokers }\end{array}$ & 6 & II.I & 31 & 51.9 \\
\hline 4. Public places should be smoke-free & 2.8 & 1.6 & 4.8 & 90.8 \\
\hline $\begin{array}{l}\text { 5. Parents or adults should not smoke } \\
\text { near children }\end{array}$ & 2.5 & 3.8 & 12.3 & 81.5 \\
\hline 6. Campus should be smoke- free & 3.6 & 4 & 12.1 & 80.3 \\
\hline
\end{tabular}

Abbreviations: SHS, secondhand smoke; N, number.

score for attitude toward SHS exposure, the group mean was $23(\mathrm{SD}=3.1)$ with a possible range of 6-29 points. The scoring method applied indicates that higher scores show agreement with policies and procedures to reduce SHS exposure.

\section{Avoidance of SHS exposure}

The findings of the avoidance subscale (Table 3 ) reveal that the majority of students $(74.1 \%)$ will try to distance themselves from smokers to avoid the negative effects of SHS on health by choosing the responses "almost always true" or "usually true" versus the responses "usually not true" and "almost never true." On the other hand, $57.2 \%$ of students responded that they would allow people to smoke in their homes and would not leave a group of people if someone starts smoking in the group (60.1\%). Although many (40.7\%) of the participants would not let people smoke in their car; however, 54.4\% would join their friends in smoking areas, and more than half (73.2\%) reported SHS to be offensive. Finally, the majority of respondents (63.3\%) acknowledged that they routinely associate with people who smoke. When summed to create a total score for the Avoidance SHS scale, the group mean was $46.4(\mathrm{SD}=8.4)$ with total score means ranging from 18-72 points. The scoring method applied indicates that higher scores describe more avoidance behavior. There was a significant difference in the mean avoidance score between males $(\mathrm{M}=45.18 ; \mathrm{SD}=8.13)$ and females $(\mathrm{M}=47.41 ; \mathrm{SD}=8.55)$ in our study; $t(789)=(3.75)$; $P=0.0002$.

Further, to test the effect of household smoking practices and exposure on the student's avoidance behavior, we conceptualized three main groups: (Group 1) students who had nonsmoking household members; (Group 2) students who had smoking household members who strictly smoke outdoors; and (Group 3) students who had smoking household members who smoke indoors. To provide

Table 2 Findings of knowledge, attitudes, preventive efforts to avoid SHS exposure scale $(\mathrm{N}=800)$

\begin{tabular}{|c|c|c|c|c|c|}
\hline & $\begin{array}{l}\text { Strongly } \\
\text { disagree \% }\end{array}$ & Disagree \% & Undecided \% & Agree \% & $\begin{array}{l}\text { Strongly } \\
\text { agree \% }\end{array}$ \\
\hline \multicolumn{6}{|l|}{ Knowledge } \\
\hline $\begin{array}{l}\text { Smoke from other people's cigarettes } \\
\text { is harmful for me }\end{array}$ & 5.6 & 7.6 & 20.6 & 30.6 & 35.6 \\
\hline $\begin{array}{l}\text { SHS causes heart disease and lung } \\
\text { cancer of nonsmokers }\end{array}$ & 2.1 & 4.4 & 18 & 30 & 45.5 \\
\hline SHS causes low birth weight & 2.3 & 2 & 34.6 & 30.9 & 30.3 \\
\hline $\begin{array}{l}\text { SHS makes the health of the people } \\
\text { around me worse }\end{array}$ & 2.1 & 3.8 & 5.8 & 35.6 & 52.8 \\
\hline \multicolumn{6}{|l|}{ Attitudes } \\
\hline $\begin{array}{l}\text { Smoke from other people's cigarettes } \\
\text { will shorten my life }\end{array}$ & 1.8 & 3.3 & 3.8 & 35.8 & 55.5 \\
\hline I let visitors smoke in my home & 20.6 & 17.8 & 23.5 & 30.5 & 7.6 \\
\hline I ask people to put their cigarettes out & 8.4 & 15.8 & 26.3 & 27 & 22.6 \\
\hline $\begin{array}{l}\text { Smoking should be banned in all public } \\
\text { places }\end{array}$ & 2.9 & 3.4 & 6.1 & 28.3 & 59.4 \\
\hline
\end{tabular}

Abbreviations: SHS, secondhand smoke; N, number. 
Table 3 Findings for the avoidance SHS exposure scale $(\mathrm{N}=800)$

\begin{tabular}{|c|c|c|c|c|}
\hline & $\begin{array}{l}\text { Almost always } \\
\text { true \% }\end{array}$ & Usually true \% & $\begin{array}{l}\text { Usually not } \\
\text { true } \%\end{array}$ & $\begin{array}{l}\text { Not almost } \\
\text { never true \% }\end{array}$ \\
\hline $\begin{array}{l}\text { I. When I encounter someone who is smoking, I distance } \\
\text { myself to unsure that I will not be exposed to smoke }\end{array}$ & 28.4 & 45.8 & 17.8 & 8 \\
\hline 2. I allow people to smoke in my home & I7.1 & 40 & 25.4 & 17.5 \\
\hline $\begin{array}{l}\text { 3. If I am with a group of people, and someone begins to } \\
\text { smoke, I will remain with the group }\end{array}$ & 22.5 & 37.6 & 28 & 11.9 \\
\hline $\begin{array}{l}\text { 4. If I encounter a friend or relative who is smoking, I will } \\
\text { sit and talk with him/her while he/she is smoking }\end{array}$ & 24.5 & 38.6 & 25.3 & 11.6 \\
\hline $\begin{array}{l}\text { 5. When I am in public place such as restaurant or offices or } \\
\text { clinic, I will leave if unable to sit in the nonsmoking section }\end{array}$ & 19.3 & 28.4 & 30.7 & 21.6 \\
\hline $\begin{array}{l}\text { 6. When I trip by bus, or any other public transportation } \\
\text { I would request a nonsmoking seat }\end{array}$ & 16.1 & 17.1 & 30.4 & 36.4 \\
\hline 7. When I trip by taxi I will ask the driver not to smoke & 17 & 21 & 33 & 29 \\
\hline 8. I allow people smoking in the car & 13.6 & 27.1 & 29.2 & 30.1 \\
\hline $\begin{array}{l}\text { 9. If my friends or relatives are gathering in a designated } \\
\text { smoking area to smoke, I will join them rather than be alone }\end{array}$ & 22 & 32.4 & 24.4 & 21.3 \\
\hline $\begin{array}{l}\text { 10. If I am with people who are smoking and I cannot leave, } \\
\text { I will ask them to refrain from smoking }\end{array}$ & 29.9 & 28.4 & 25.9 & 15.9 \\
\hline \multirow{2}{*}{$\begin{array}{l}\text { II. I will sit in the smoking section of a public place or bus } \\
\text { station if there are no seats available elsewhere }\end{array}$} & 24.4 & 35.8 & 22 & 17.8 \\
\hline & $\begin{array}{l}\text { Almost always } \\
\text { true \% }\end{array}$ & Usually true \% & $\begin{array}{l}\text { Usually not } \\
\text { true \% }\end{array}$ & $\begin{array}{l}\text { Never not } \\
\text { true \% }\end{array}$ \\
\hline $\begin{array}{l}\text { 12. When an outdoor functions where smoking is present, } \\
\text { I will move away to avoid it }\end{array}$ & 33.3 & 40.1 & 16.5 & 10.1 \\
\hline $\begin{array}{l}\text { 13. When an outdoor functions where waterpipe smoking } \\
\text { is present, I will move a way to avoid it }\end{array}$ & 29.5 & 33.8 & 19.4 & 17.3 \\
\hline $\begin{array}{l}\text { 14. When exposed to SHS, I wash my clothes solely to } \\
\text { remove the smell of smoke from them even if they } \\
\text { are otherwise clean }\end{array}$ & 36.8 & 21.1 & 24.3 & 17.8 \\
\hline 15. I find it unpleasant to be around SHS & 34 & 23.8 & 19.2 & 23 \\
\hline 16. I routinely associate with people who smoke & 29.8 & 33.5 & 21.7 & 15 \\
\hline 17. When eating out, I always sit in the nonsmoking section & 32 & 30 & 24.2 & 13.8 \\
\hline 18. I don't frequently places where smoking is prevalent & 32 & 30 & 24.2 & 13.8 \\
\hline 19. I do not find SHS offensive & 13 & 13.9 & 17.9 & 55.3 \\
\hline
\end{tabular}

Abbreviations: SHS, secondhand smoke; N, number.

a more comprehensive comparison between the three groups - (Group 1) nonsmoking household members; (Group 2) smoking household members who smoke outdoors; and (Group 3) smoking household members who smoke indoors - according to the presence of household smoking, a composite scale was compiled for the three scales used in the questionnaire (knowledge, attitude, and avoidance).

The avoidance scale scores for each of the three groups are summarized in Table 4 (overlapped by sex). The respondents are assumed independent and normal with respect to each other, even though they were not randomly selected, as evident by the quantile plot distribution patterns, which are used to gauge the normality of the scores for each group. ${ }^{22}$

The one-way ANOVA was used to test for mean avoidance behavior differences among the three respondents' groups. Avoidance behaviors differed significantly across the three groups $(\mathrm{F}[2,797]=7.9 ; P=.0004)$. Tukey post hoc comparisons of the three groups indicate that Group 1, the nonsmoking household members, had significantly higher avoidance behavior than Group 3, the smoking household members who smoke indoors $(P=0.0002)$. Comparisons between Group 2, the smoking household members who smoke outdoors, and the other two groups were not statistically significant $(P>0.05)$. Furthermore, when analyzed by sex, avoidance behaviors did not differ significantly across the three groups within male respondents $(\mathrm{F}[2,358]=2.8 ; P=0.0621)$. However, avoidance behaviors differed significantly across the three groups within female respondents $(\mathrm{F}[2,436]=10.00 ; P<0.0001)$. Tukey post hoc comparisons of the three groups within females indicate that Group 1's nonsmoking household members had significantly higher avoidance behavior than Group 3's smoking household members who smoke indoors $(P<0.0001)$. Comparisons between Group 2's smoking household who smoke outdoors and the other two groups were not statistically significant $(P>0.05)$. 
Table 4 Avoidance scores by household smoking status and sex $(\mathrm{N}=800)$

\begin{tabular}{llll}
\hline Group & N & Mean & SD \\
\hline Household nonsmokers & 266 & 50.8 & 8.9 \\
Household smokers, outdoors & 124 & 49.1 & 9.9 \\
Household smokers, indoors & 410 & 48.0 & 8.3 \\
Household nonsmokers, males & 146 & 49.1 & 8.5 \\
Household nonsmokers, females & 120 & 52.9 & 9.0 \\
Household smokers outdoors, males & 60 & 46.7 & 9.4 \\
Household smokers outdoors, females & 64 & 51.3 & 9.9 \\
Household smokers indoors, males & 155 & 47.0 & 7.8 \\
Household smokers indoors, females & 255 & 48.7 & 8.5 \\
\hline
\end{tabular}

Abbreviations: N, number; SD, standard deviation.

\section{Discussion}

Jordan was one of the first countries in the region to establish comprehensive smoke-free policies. However, the results of the present study demonstrated that approximately half of the students reported that their universities did not enforce smokefree policies, and one-fifth reported that they did not know if such policies existed. Also, more than half of the students reported that they had not attended lectures or programs related to smoking. This result might be explained by the fact that smoking and SHS health effects are not integrated into the universities' health communication programs about SHS avoidance. Therefore, smoke-free policies should be enforced by promoting a healthy understanding about the hazards of smoking and adopting serious legislation in all Jordanian universities.

\section{Household SHS exposure}

The current study shows that SHS exposure among nonsmoking students in northern Jordan is very high in general and in the home environment in particular. The findings of the current study are consistent with the findings of Maziak et al, ${ }^{23}$ who used a sample of adult nonsmokers from the Aleppo Household Survey in Syria. They also found comparably high levels of SHS exposure at the home level.

Smoking among males is very prevalent in Jordan $(62.7 \%)$; males also function as the head of most households. ${ }^{17}$ Moreover, there is sex inequality in Jordan that is evident by the global sex gap index that ranks Jordan among the countries with the highest sex inequality in the world. ${ }^{24}$ Thus, it is not uncommon to find the home environment in Jordan permissive of smoking. Further, there is a cultural aspect that poses a barrier against establishing smoke-free homes in Jordanian society. Jordanians will find it extremely difficult and would be perceived as inhospitable to their guests if they were to deny their guests smoking during a visit. ${ }^{17}$ Thus, limiting SHS exposure in the home environment has many barriers to overcome.

\section{Students' knowledge and attitudes toward SHS exposure}

The results showed that all students mostly agreed or strongly agreed that smoking should be banned in all public places $(88 \%)$. This result reflected a greater level of agreement with such policies than the previous findings of Ridner et $\mathrm{al},{ }^{25}$ which provides more support to smoke-free policies in universities in Jordan. The majority of SHS studies reveal that both smokers and nonsmokers believe that living and working with a smoker could affect the health of nonsmokers. However, nonsmokers were more likely to agree with this position. ${ }^{26,27}$ In our sample, the majority demonstrated sound knowledge and favorable attitudes toward the risk of SHS exposure. Students either agreed or strongly agreed with all the items assessing knowledge or attitudes in our instrument.

\section{Avoidance of SHS exposure}

The results revealed that females have significantly higher levels of SHS exposure avoidance. This result was consistent with the study conducted by Maziak et $\mathrm{al}^{27}$ in Syria where they investigated the magnitude of exposure among the adult population and found significantly high exposure. Furthermore, Li and Wang ${ }^{28}$ conducted a study in southern Taiwan to investigate the correlation of behavior to avoid SHS in adolescents. These results also demonstrated that SHS avoidance behavior for female adolescents was greater than that of male adolescents. A possible explanation could be related to female characteristics that help them to maintain positive attitudes toward SHS exposure, including being a nonsmoker, having fewer smoking peers, and having more awareness and feelings of responsibility. Accordingly, the findings of this study suggest that more university-based public health efforts could be tailored toward male university students in Jordan to promote SHS exposure avoidance among nonsmokers and improve the acceptance of nonsmoking restrictions among smokers.

Among each sex, we conceptualized three exposure groups regarding avoidance. The results showed that females who lived in households where no one smoked had a significantly higher overall avoidance score in general, compared to females who lived in smokers' households where smoking was permitted. This indicates that the permissive environment at home should be shaping the overall behavior 
of female students. On the other hand, we did not find such an outcome in the male student population of the study. We cannot identify a direct reason from the literature. However, this could be dose-dependent, based on how much time males and females spend at home, with the assumption that females have less freedom and spend more time in their homes than male students. Unfortunately, we did not attempt to account for this variable in the survey; thus, we cannot test this assumption in the current study. Nevertheless, our study showed that living with smokers has a negative impact on a nonsmoker's ability to avoid SHS exposure. Gharaibeh et $\mathrm{al}^{17}$ encountered a similar finding in our previous work that measured secondhand smoking avoidance among females in Jordan. They reported that if a Jordanian woman lives with a smoker, it has a significant impact on her ability to avoid SHS exposure.

Our results suggest that even if a student has knowledge of the dangers of SHS and appropriate avoidance behaviors, he or she is often unable to avoid SHS, as students often reported high hours of exposure. This discrepancy is likely influenced by cultural factors. Smoking is an accepted habit, and it is disrespectful to discuss smoking cessation with a smoker if he is an elder. Hospitality is encouraged, but it also discourages the person from restricting smoking in his/her home. This result can provide a strong indicator that smoke-free policies are not effective in all universities. More efforts are needed to alter and enforce these policies. Therefore, the result of the present study supports the need to integrate smoking and SHS exposure issues into university curricula in elective courses. In addition, the social norm toward smoking and SHS exposure must be altered by raising public awareness about the risks of smoking and SHS exposure.

\section{Limitations}

Our study had a number of limitations. First, the generalization of the findings is potentially limited because a convenience sample was used from the northern part of Jordan and public universities only. Second, because a self-reporting instrument was used to collect the data from the participants in our study, this may have resulted in recall bias.

\section{Recommendations}

Replication of this study using smoking and nonsmoking students in public and private universities is recommended to determine the differences between these groups. Furthermore, efforts should be made to activate and to enforce smoke-free policies in all settings. Future research is also needed to highlight the role that culture plays on SHS exposure and the effect of smoke-free policies on reducing exposure to SHS. Finally, there exists an urgent need for community education and public awareness campaigns to empower younger generations to establish smoke-free environments.

\section{Conclusion}

The present study provides descriptive information about the current SHS exposure rate among Jordanian university students. Similar to the only other Jordanian study ${ }^{17}$ on SHS exposure, this study reveals a high exposure rate among university students. Universities should play an active role in designing education programs that help reduce exposure to SHS. Thus, the findings of this study support further enforcement of smoke-free policies in all environments. Jordan prohibits smoking in public places and workplaces, yet compliance with antismoking laws is extremely poor in most locations. This may be because more than half of Jordanian men smoke. ${ }^{2}$ Advocacy for effective interventions to avoid exposure to SHS should be initiated among Jordanian society as a whole.

\section{Acknowledgments}

The study was funded by the Jordan University of Science and Technology, Deanship of Scientific Research, and Deanship of Graduate Studies.

\section{Disclosure}

The authors report no conflicts of interest in this work.

\section{References}

1. World Health Organization. WHO Report on the Global Tobacco Epidemic, 2009: The MPOWER Package. Geneva, Switzerland: World Health Organization Press; 2009.

2. The Economist Intelligence Unit Limited. Tomorrow's Regular Customers? Stamping Out Tobacco Use in the Middle East and Africa. London, United Kingdom: The Economist; 2009.

3. Centers for Disease Control and Prevention. Assessing risk factors for chronic disease - Jordan, 2004. MMWR Morb Mortal Wkly Rep. 2006; 55(23):653-655.

4. Belbeisi A, Al-Nsour M, Batieha A, Brown DW, Walke HT. A surveillance summary of smoking and review of tobacco control in Jordan. Global Health. 2009;5:18:5-18.

5. Al-sheyab N, Gallagher R, Gallagher P, Shah S. Cigarette smoking in adolescents with asthma in Jordan: impact of peer-led education in high schools. J Nursing Ed. 2013;3(9):13-22.

6. Research for International Tobacco Control, WHO Report on the Global Tobacco Epidemic: The MPOWER Package, 2008. Geneva, Switzerland: World Health Organization Press; 2008.

7. Ministry of Health. The Hashemite Kingdom of Jordan Ministry of Health: Annual Statistical Book. Jordan; 2008; Available from: http:// www.moh.gov.jo/MOH/Files/Publication/report2008_1.pdf. [Arabic].

8. Haddad L, Al-Zyoud S, Abu-Baker NN, Gharaibeh H, El-Shahawy O, Alramadhani R. Secondhand smoking in Jordan: clearing the air for one of the highest tobacco prevalence countries in the Middle East. Tobacco Use Insights. 2011;4:1-7. 
9. Khader YS, Alsadi AA. Smoking habits among university students in Jordan: prevalence and associated factors. East Mediterr Health J. 2008;14(4):897-904.

10. World Health Organization, 2010. Fact sheet No. 339. Tobacco. [webpage on the Internet]. Available at: http://www.who.int/mediacentre/ factsheets/fs339/en/index.html. Accessed November 12, 2010.

11. Glantz SA, Jamieson P. Attitudes toward secondhand smoke, smoking, and quitting among young people. Pediatrics. 2000;106(6):e82.

12. Abu-Baker NN, Haddad L, Savage C. The influence of secondhand smoke exposure on birth outcomes in Jordan. Int J Environ Res Public Health. 2010;7(2):616-634.

13. SACTob (Scientific Advisory Committee on Tobacco Product Regulation), 2003. Recommendation on health claims derived from ISO/ FTC method to measure cigarette yield. Available from: http://www. who.int/tobacco/sactob/recommendations/en/iso_ftc_en.pdf. Accessed November 12, 2010

14. WHO.int [homepage on the Internet]. Why is tobacco a public health priorty? World Health Organization; 2007; Available at http://www.who. int/tobacco/health_priority/en/index.html. Accessed December 7, 2012.

15. WHO.int [homepage on the Internet]. Only 100\% smoke-free environments adequately protect from dangers of secondhand smoke. World Health Organization; 2007; available http://www.who. int/mediacentre/news/releases/2007/pr26/en/print.html. Accessed December 1, 2012.

16. World Health Organization Statistical Information System. World Health Statistics 2007. Geneva: World Health Organization; 2007. Available from http://www.who.int/whosis/whostat2007_10highlights. pdf. Accessed December 7, 2012.

17. Gharaibeh H, Haddad L, Alzyoud S, El-Shahawy O, Abu-Baker N, Umlauf M. Knowledge, attitudes, and behavior in avoiding secondhand smoke exposure among nonsmoking employed women with higher education in Jordan. Int J Environ Res Public Health. 2011;8(11):4207-4219.
18. Wipfli H, Avila-Tang E, Navas-Acien A, et al. Secondhand smoke exposure among women and children: evidence from 31 countries. Am J Public Health. 2008;98(4):672-679.

19. Glasgow RE, Foster LS, Lee ME, Hammond SK, Lichtenstein E, Andrews JA. Developing a brief measure of smoking in the home: description and preliminary evaluation. Addict Behav. 1998;23(4): $567-571$.

20. Kurtz ME, Kurtz JC, Contreras D, Booth C. Knowledge and attitudes of economically disadvantaged women regarding exposure to environmental tobacco smoke: a Michigan, USA, study. Eur J Public Health. 2003;13(2):171-176.

21. Martinelli AM. Testing a model of avoiding environmental tobacco smoke in young adults. Image J Nurs Sch. 1999;31(3):237-242.

22. Thode Jr, Henry C. Testing for Normality. New York: Marcel Dekker Inc; 2002.

23. Maziak M, Ward KD, Rastam S, Mzayek F, Eissenberg T. Extent of exposure to environmental tobacco smoke (ETS) and its dose-response relation to respiratory health among adults. Respir Res. 2005;6:13.

24. World Economic Forum. The Global Gender Gap Report. Switzerland; 2010. Available from http://www3.weforum.org/docs/WEF_ GenderGap_report_2010.PDF. Accessed February 13, 2013.

25. Ridner SL, Hahn EJ, Staten R, Miller K. Attitudes toward secondhand smoke among college students. South Online J Nurs Res. 2006;1(7):1-14.

26. Madanat H, Barnes MD, Cole EC. Knowledge of the effects of indoor air quality on health among women in Jordan. Health Educ Behav. 2008;35(10):105-118.

27. Maziak W, Ward KD, Eissenberg T. Measuring exposure to environmental tobacco smoke (ETS): a developing country's perspective. Prev Med. 2006;42(6):409-414.

28. Li MF, Wang RH. Factors related to avoidance of environmental tobacco smoke among adolescents in southern Taiwan. J Nurs Res. 2006;14(2):103-112.
Substance Abuse and Rehabilitation

\section{Publish your work in this journal}

Substance Abuse and Rehabilitation is an international, peer-reviewed, open access journal publishing original research, case reports, editorials, reviews and commentaries on all areas of addiction and substance abuse and options for treatment and rehabilitation. The manuscript management system is completely online and includes a very quick and fair

\section{Dovepress}

peer-review system. Visit http://www.dovepress.com/testimonials.php to read real quotes from published authors. 